\title{
Integrating qualitative system dynamics with accounting practices: The case of integrated reporting and resource mapping
}

\author{
Maria Cleofe Giorgino $^{1}$ | Federico Barnabè ${ }^{1}$ | Martin Kunc ${ }^{2}$
}

\footnotetext{
${ }^{1}$ Department of Business and Law, University of Siena, Siena, Italy

${ }^{2}$ Southampton Business School, University of Southampton, Southampton, UK

Correspondence

Martin Kunc, Southampton Business School, University of Southampton, University Road, Southampton SO17 1BJ, UK.

Email: m.h.kunc@soton.ac.uk
}

\begin{abstract}
The article explores the role of qualitative system dynamics (SD) in evaluating the information presented in corporate accounting reports. Particularly, this study focuses on a recent corporate report called integrated reporting $(<\mathrm{IR}>)$, and analyses the $<\mathrm{IR}>$ information using a specific qualitative SD technique, resource mapping, in order to visualize the key resources and their connections responsible for the performance of the organization. The study's contribution is twofold. First, it provides insights on how to apply qualitative SD in the field of management accounting and corporate reporting. Second, it verifies the benefits of combining qualitative SD and corporate reporting tools to develop new knowledge useful to represent and face the dynamic complexity implicit in a business domain.
\end{abstract}

\section{KEYWORDS}

dynamic complexity, integrated reporting, management accounting, qualitative system dynamics, resource mapping

\section{1 | INTRODUCTION AND BACKGROUND TO THE RESEARCH}

A wide literature debated the various typologies of data used for building models in system dynamics (SD; Forrester, 1961, 1968; Richardson \& Pugh, 1981; Sterman, 2000). As Forrester (1980) states, data can be primarily divided into three categories, that is, mental data, written data, and numerical data, which differ on their level of formalization, amount, and availability. Among them, written data certainly represent an "excellent source of information about system structure and the reasons for decisions" (Forrester, 1980, p. 557), particularly in the business domain, where a widely available source of data are corporate reports. Different types of corporate reports that provide more qualitative information, specifically to improve the relationship between the organization and its stakeholders, are becoming increasingly relevant
(Deegan \& Blomquist, 2006; Gray, Kouhy, \& Lavers, 1995). Thus, these reports can be a good written database for the development of SD models, as implicitly suggested by many scholars (e.g., Kim \& Andersen, 2012; Kunc \& Morecroft, 2009; Luna-Reyes \& Andersen, 2003; Richardson \& Pugh, 1981; Schaffernicht, 2010; Sterman, 2000). Moreover, there is an increasing number of studies based on the use of different variations of qualitative SD, such as causal loop diagramming (e.g., Senge, 1990; Wolstenholme, 1999), cognitive mapping (e.g., Eden, 1992), and resource mapping (e.g., Kunc \& Morecroft, 2009; Kunc \& O'Brien, 2017). Indeed, SD literature offers the breadth of application, and the potentials of qualitative SD for the inspection and analysis of various managerial problems (e.g., Coyle \& Alexander, 1997; Gary \& Wood, 2011; Kopainsky \& Luna-Reyes, 2008; Lane, 2008; Pala, Vennix, \& Van Mullekom, 2003; Snabe \& Größler, 2006; Wolstenholme \& Coyle, 1983). 
However, previous research also raised some concerns on the use of qualitative SD. More in detail, there are some challenges within the academic community (e.g., the challenge of increasing the degree of transparency and structure analysis in qualitative SD models, Martinez-Moyano, 2012; of improving the accuracy of mental models, Schaffernicht \& Groesser, 2011; or of ameliorating the analysis of qualitative SD models through the investigation of a selected number of system characteristics, such as the no. of variables, the no. of loops, and the length of loops included in the model, see Schaffernicht \& Groesser, 2014), as well as calls for action and more evidence of the potentials and usefulness of qualitative SD models, in comparison with (or for integration with) quantitative modelling (Wolstenholme, 1999). Particularly, the effectiveness of qualitative SD models is still at the centre of a very lively debate and requires in-depth analyses in terms of its potentials to represent and evaluate the dynamic complexity inherent in an organization's business activities (Groesser, 2013), which is ultimately embedded in its corporate reports. On this point, the aim of our study is two-fold:

1. to provide insights on how to apply qualitative SD in the field of management accounting and corporate reporting by re-organizing and re-framing existing data and information into new dynamic-oriented knowledge; and

2. to investigate the dynamic complexity expressed in a comprehensive corporate report and evaluate the role of qualitative SD to represent dynamic complexity and support decision-makers.

In sum, the main expected contribution of this study is to verify the usefulness of combining qualitative SD and corporate reporting tools to both re-frame the written information of these documents through specific visual artefacts and develop additional knowledge about the value creation process of an organization.

To achieve this aim, the study focuses on a specific qualitative SD method, that is, resource mapping (Kunc \& Morecroft, 2009), applied to a recent type of corporate reports-the so-called Integrated Reporting (hereafter $<$ IR $>$ ) - selected for being a written text including also many qualitative information on the social and environmental impacts of the organization's activities (IIRC, 2013a). Moreover, $<I R>$ is currently at the centre of a very active debate involving both academics in management accounting and practitioners worldwide (e.g., Adams, 2015; de Villiers, Rinaldi, \& Unerman, 2014; Eccles \& Krzus, 2011; Giorgino, Supino, \& Barnabè, 2017). In a second step, our analysis employs a quantitative tool, that is, SDM-Doc (Martinez-Moyano, 2012), to analyse the dynamic complexity represented and embedded in the <IR $>$-based resource map developed. Particularly, the analysis of the maps performed with the SDMDoc software allows investigating specific properties of the structure of qualitative SD modelling (Groesser \& Schaffernicht, 2012; Schaffernicht \& Groesser, 2011, 2014).

This study expects to verify the utility of combining $<$ IR $>$ with qualitative SD (specifically with resource mapping) as a method to increase the information content of an integrated report and support decision-makers in understanding the dynamic complexity.

\section{2 | TOWARDS THE COMBINATION OF SYSTEM DYNAMICS WITH INTEGRATED REPORTING}

Scholars have demonstrated the validity of combining SD tools and principles with strategic management, accounting, and reporting tools and frameworks (e.g., Barnabè, 2016; Gary, Kunc, Morecroft, \& Rockart, 2008; Kunc \& Morecroft, 2007; Snabe \& Größler, 2006; Warren, 2008). Examples include the combination of SD with balanced scorecard (Akkermans \& Van Oorschot, 2005; Barnabè \& Busco, 2012; Capelo \& Ferreira Dias, 2009; Humphreys, Gary, \& Trotman, 2015) and with the data envelopment analysis (e.g., Lacagnina \& Provenzano, 2009, 2011). Overall, this stream of literature highlights the benefits of combining SD with other tools/techniques for: elicitation of mental models (Ford \& Sterman, 1998; Vennix, 1996), increased participation of stakeholders in decision-making (Stave, 2002), improved corporate performance (Warren, 2008), identification of linkages between strategy and operations (Morecroft, 2007), understanding of the potential side-effects and counterintuitive results generated by policies (Forrester, 1971), and mitigation of bounded rationality in decision-making (Größler, 2004).

However, a further combination of SD with additional management, accounting, and reporting tools is advocated particularly by non-SD scholars (e.g., Kaplan, 2012), but there have not been studies satisfying this request. This study aims to address such a gap in the literature by investigating the usefulness of combining SD principles with a recent corporate reporting tool (i.e., the integrated report) developed by the International Integrated Reporting Council (IIRC) in order to represent and communicate in one document the overall process of value creation.

According to the IIRC framework (IIRC, 2013a), an $<$ IR $>$ has to contain all the elements describing the organization's activities and support the process of value 
creation involving organization's stakeholders through the use of specific guidelines, such as connectivity and materiality. Connectivity entails representing the interrelatedness and dependencies among the different factors (e.g., the various resources or financial and non-financial information) influencing the organization's capacity to create value over time. Materiality requires disclosing all factors impacting the organization's value creation process.

In the IIRC framework, the organization's inputs (the resources/capitals at disposal) are classified into six categories (IIRC, 2013b): Financial, Manufactured, Human, Intellectual, Social, and Natural. Overall, an $<\mathrm{IR}>$ represents the value creation process as a dynamic and circular system because the economic and non-economic outcomes produced by the organization affect the future organization's availability of inputs for successive production cycles (Figure 1).

In broad terms, the $<\mathrm{IR}>$ 's ultimate goal is to inform the organization's shareholders and stakeholders about the value created using the inputs at disposal (IIRC, 2013a, p. 35). Unfortunately, this goal inevitably clashes with the difficulties in "capturing" the dynamic complexity affecting the organization's activities, defining the system boundaries, and identifying which relationships and outcomes have to be included in the model of the organization.

Therefore, this study integrates the $<\mathrm{IR}>$ perspective on value creation (and the written database delivered by the report itself) with an SD approach to provide more insights into the performance of the organization, thus investigating if this combination may be fruitful to encourage more cross-fertilization between SD and the field management accounting.

In detail, this study applies qualitative SD in the form of resource mapping (Kunc \& Morecroft, 2009), an SD technique adopting a particular graphical toola resource map - to visualize the key strategic resources, their connections, and the overall pattern of value creation. Resource maps are essentially stock and flow diagrams (Sterman, 2000), so they overcome some of the weaknesses of causal loop diagrams in terms of understanding the dynamics of the system structures (Schaffernicht, 2010). In resource maps, "stocks" represent diagrammatically resources or asset stocks using the description suggested in Barney (1986) and Dierickx and Cool (1989). "Flows" depict increases and decreases in the level of resources, controlled by implicit or explicit operating policies (Kunc, 2007). Finally, a web of "connectors" represents the perceived causal attributions that, through operating policies, link resources to the accumulation rate of other resources in the organization.

In the business domain, resource maps are primarily meant to assist organizations to visualize their strategy (Kunc \& Morecroft, 2009, 2010) and the fundamental architecture according to which the specific business system operates (Warren, 2008). They also act as visual

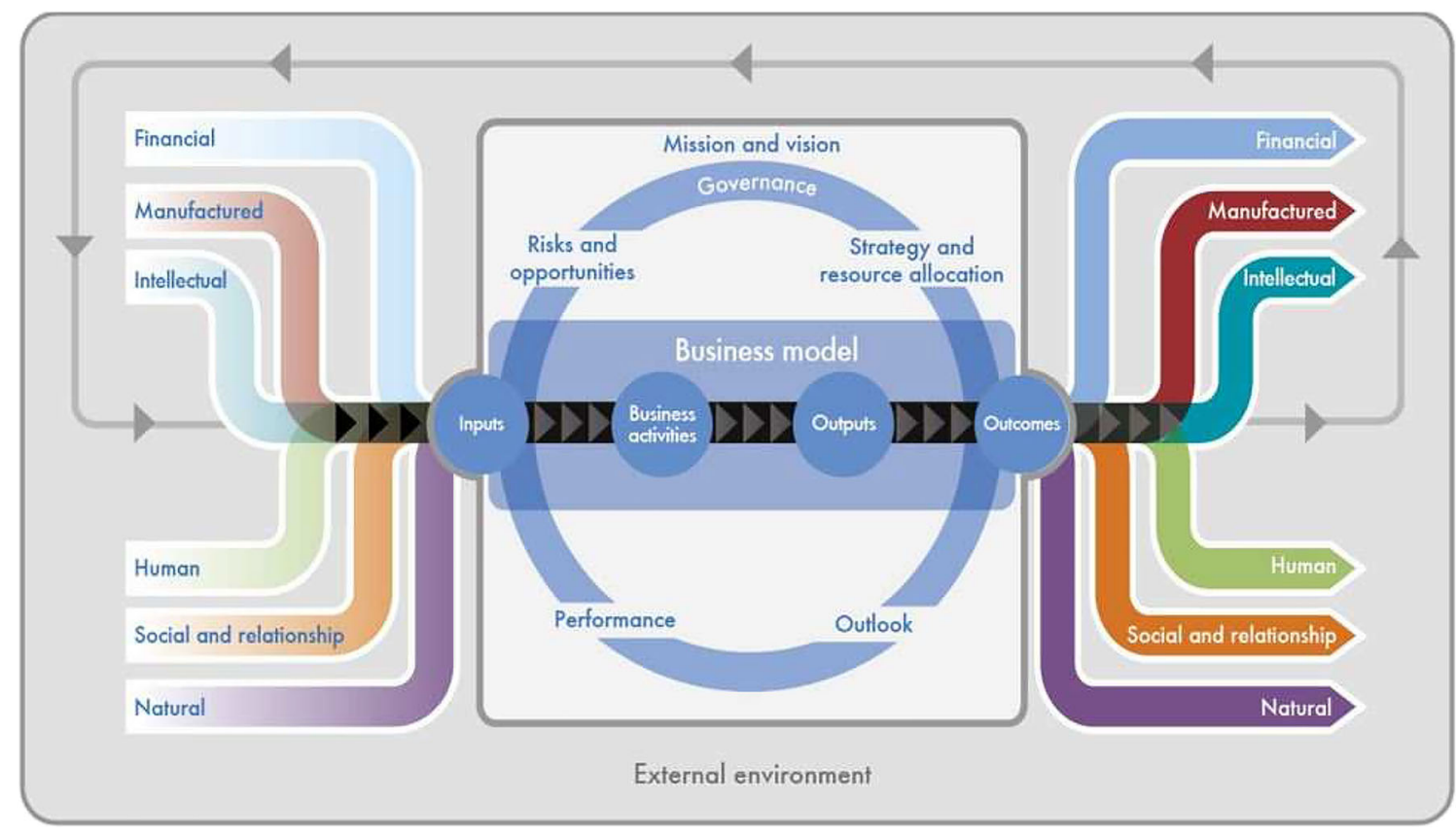

Value creation (preservation, diminution) over fime

FIGURE 1 Business model functioning and positioning (IIRC, 2013a, p. 13) [Colour figure can be viewed at wileyonlinelibrary.com] 
representations of the network of interdependencies existing both within and outside the organization, hence, demonstrating graphically the complexity existing in business models and analytically its impact on value creation through the analysis and evaluation of the feedback processes represented in a resource map (Kazakov \& Kunc, 2016). Moreover, as mentioned by Torres, Kunc, and O'Brien (2017), resource maps may introduce CEOs to the use of SD, clarifying the concepts behind SD models (stocks, flows, and integral equations) by associating them with their knowledge about the organization.

In this study, the network of stocks and flows is informed by the comprehensive reporting of business operations-the $<\mathrm{IR}>$ - in terms of resources underpinning competitive advantage and value creation. The aim pursued is to investigate the benefits of developing $<$ IR $>$-based resource maps in order to reframe the $<$ IR $>$ information and provide new knowledge useful to understand the dynamic complexity of an organization, explicitly supporting decision-makers in clearly representing key capitals/resources, explaining trade-offs between capitals, gaining policy insights (Lane, 2012), and exploiting key value creation patterns (Kim, 2001).

\section{3 | Research method}

The research design of the study consists of three consecutive steps: identification of the specific $<\mathrm{IR}>$ being analysed, development of the related $<\mathrm{IR}>$-based resource map, and analysis of the dynamic complexity resulting from the resource map. Additional details on each step are provided below.

\section{1 | Selecting the case study}

As a first step, the research design requires the selection of the specific $<\mathrm{IR}>$ to be analysed according to the aim pursued. For this study, there was the need of identifying an "exploratory case study" (Ryan, Scapens, \& Theobald, 2002; Yin, 1994) useful to explore the benefits of combining this corporate reporting tool with qualitative SD. Therefore, the selection fell on the $2015<\mathrm{IR}>$ (retrieved in date 2 December 2016) of an Italian oil and gas company, ENI, due to multiple reasons. First, ENI is considered to be an experienced organization using $<\mathrm{IR}>$ because it is one of the organizations that have joined the IIRC Pilot Programme in its beginnings and subsequently published numerous annual versions of $\langle\mathrm{IR}\rangle$. Additionally, ENI belongs to the oil and gas industry, which represents one of the most scrutinized business sectors in terms of sustainability and reporting practices (e.g., Roca \& Searcy, 2012).

\section{2 | Resource mapping process}

In a second step, the research method requires the analysis of the information included in the organization's $<\mathrm{IR}>$ (in this case, the ENI's $<\mathrm{IR}>$ ), and particularly in the section presenting the organization's business model (ENI, 2015, pp. 16-17), in order to develop the resource map representing the processes of value creation. For this step, it might be useful to adopt a specific software, such as Vensim (Eberlein \& Peterson, 1992).

Specifically, the resource mapping process entails four main activities (Kunc \& Morecroft, 2009):

- identification of the organization's resources and capabilities;

- assessment of their strength and importance in the organization's business strategy;

- graphical representation of resources, capabilities, and relationships among them using specific graphic signs (like boxes and arrows);

- identification of the dynamic complexity existing in the organization, as derived from the system represented.

To increase the study's reliability, data and information contained in the selected <IR> were analysed separately by more than one researcher in order to reduce potential "researcher effects" (Miles, Huberman, \& Saldana, 2013, p. 296). The results of the different autonomous data processing were compared to identify the "shared" resource map, including the type of causal relationships and the feedback loops involving the organization's key resources. For non-experts in the field of $\mathrm{SD}$, a feedback process consists of a circular relationship between a set of concepts (or parts of a system), for example, A affects B, then B affects $\mathrm{C}$, and ultimately $\mathrm{C}$ affects A determining a circular relationship between A, B, and C. Feedback processes are recognized and labelled as either reinforcing (positive, amplifying change) or balancing (negative, generating equilibrium), depending on the number and typologies of the relationships, for example, the number of negative linkages connecting such variables. In broad terms, a positive (or direct) relationship between two variables means that an increase (or a decrease) in the first one will lead to an increase (or a decrease) in the second one as well; on the contrary, a negative (or indirect) relationship means that an increase (a decrease) in the first one will lead to a decrease (an increase) in the second one (Sterman, 2000). 


\subsection{Analysis of the dynamic complexity in qualitative SD}

Finally, the research method requires the identification of measures useful to evaluate the dynamic complexity characterizing the system represented in the resource map, such as the number of components (stocks, flows, and auxiliaries) with their type of relationships (positive or negative linkages; Spector, Christensen, Sioutine, \& McCormack, 2001), as well as the feedback loops affecting the stocks or specific variables. It is noteworthy to remind that the identification of feedback processes in a resource map is crucial to provide clear and transparent information to the various organization's stakeholders about the critical areas of the business underpinning value creation.

The approach to evaluating structural dynamic complexity is originated from the work of Schaffernicht (2010) and Schaffernicht and Groesser (2011) related with comparing mental models of dynamic systems. According to their work, the structure of models can be analysed at three levels: the level of the elements (variables, linkages per variable, ratio between in/out linkages, and ratio between positive and negative linkages), the level of the individual feedback loop (size) and the level of the complete model (total number of feedback loops and positive and negative feedback loops). In this perspective, (see Groesser \& Schaffernicht, 2012, p. 49) "causal links, link strength, link polarities, variables, feedback loops, and, less often, other properties such as length of a feedback loop" are viewed as a core set of elements that can be used to operationalize the structural representation of a mental model of dynamic systems. Stated differently, studying and understanding the model structure enables the researcher to analyse the key "properties" of the system under investigation, thus triggering important implications.

For example, measuring the average loop length allows deriving useful information both on the structure of the system and the managers' mental models: as to the former, a higher loop length indicates that some business components are more interconnected than others (Doyle, Radzicki, \& Trees, 2008); as to the latter, and citing the work by Verburgh (1994, p. 50), an increase in the average length of loops can "be seen as an increase in the awareness that changes in one element of the system do not only result in a change in one other element, but that this next element is bringing about a change in other elements as well."

Additionally, the number of bivariate causal relationships, the polarity of these relationships, and the number of immediate feedback loops between two variables determine the strength of their impact on the performance of the business (Gary \& Wood, 2011).

Last, dense resources (i.e., "spots" where there is a high number of feedback loops) can be seen as an interesting feature of not only the system under analysis but also the managers' mental models that govern such resources (Groesser \& Schaffernicht, 2012).

TABLE 1 Steps of the research method

Steps Rationale

Corporate report selection The selection of a corporate report should consider the richness of the information provided beyond simple general accounting reports. For example, does the report describe resources? Are indications of investment activities related with the resources? Are the outputs of the investment activities beyond simple financial results?

Resource mapping process The resource map transforms the verbal report into a visual artefact by:

- identifying the organization's resources and capabilities;

- assessing their strength and importance in the organization's business strategy;

- representing graphically resources, capabilities, and relationships among them using specific icons;

- identifying the structure responsible for financial performance through the set of feedback processes connecting the resources, capabilities and organizational outcomes.

Analysis of the dynamic complexity
In order to evaluate the dynamic complexity characterizing the system represented in the resource map, there are a set of metrics that can be used.

- Number of components: stocks (resources), flows (investment or change processes), and auxiliaries (orgnanizational outputs and capabilities originated from resources).

- Type and number of relationships connecting the components: positive or negative linkages indicate the direction of the impact of one component onto other and number shows the potential for causal ambiguity.

- Number of feedback loops affecting specific components.

- Average loop length allows deriving useful information both on the structure of the system and the managers' mental models in terms of depth in the interconnections between components in the organization. 

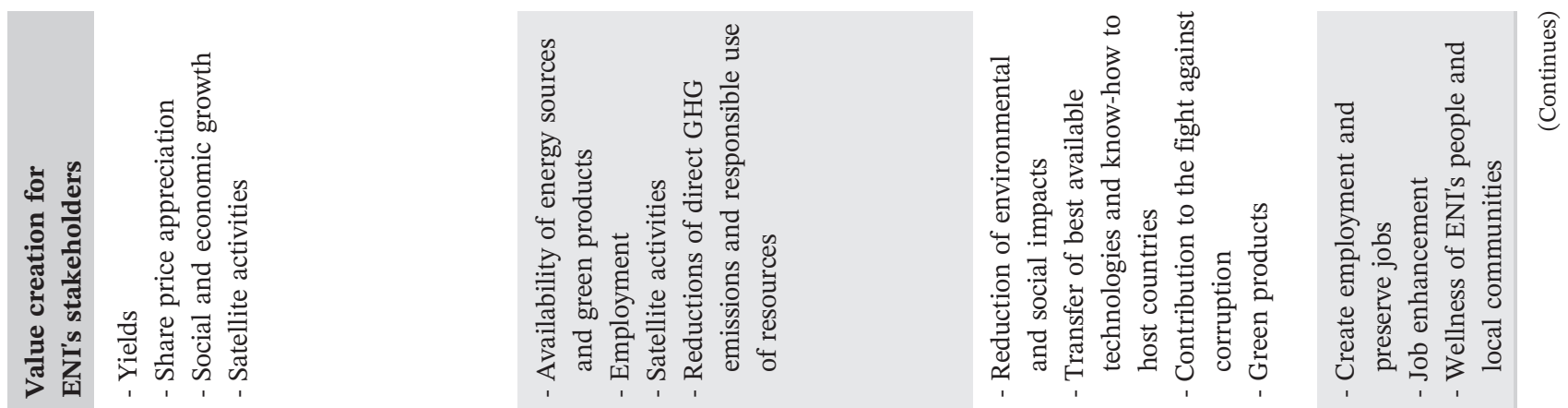

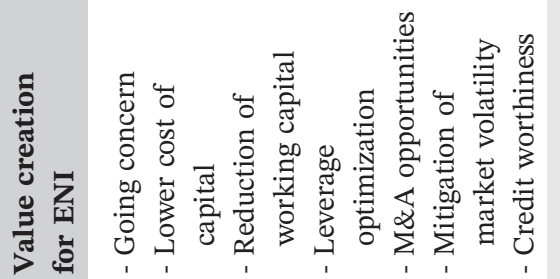

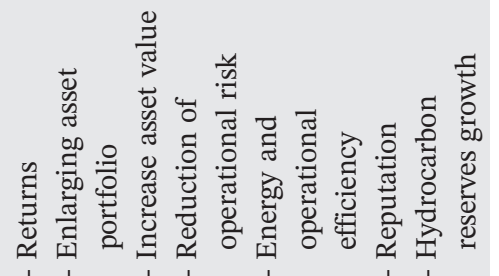

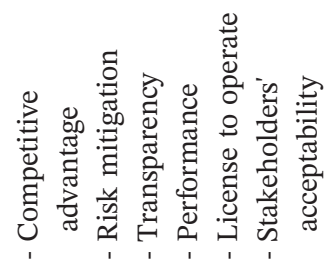

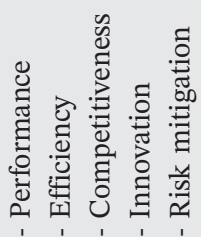

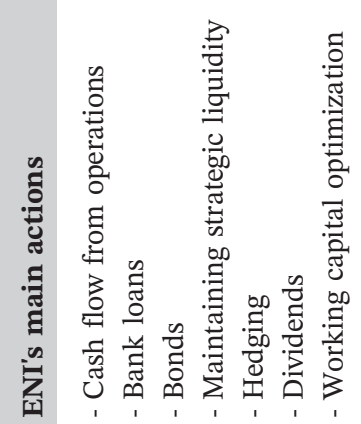
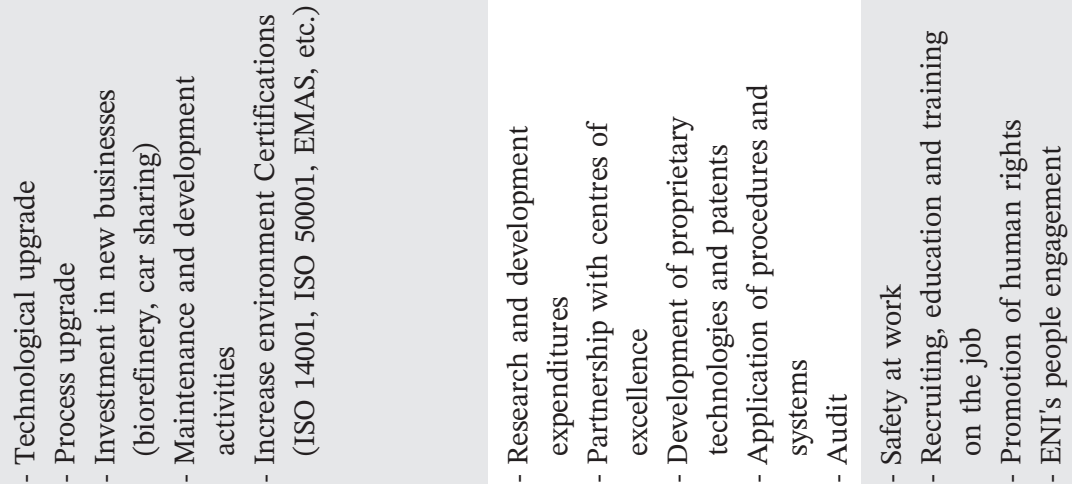

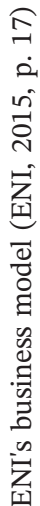
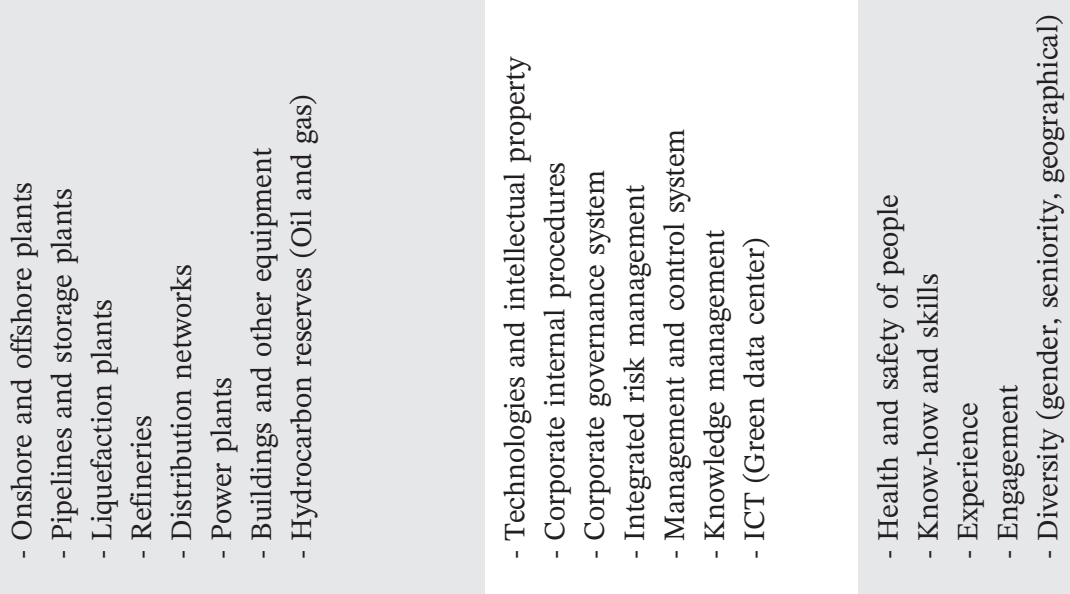

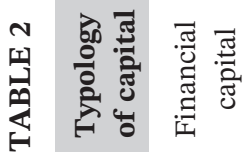

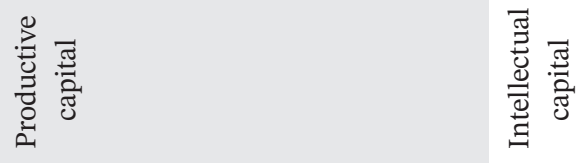

丞 

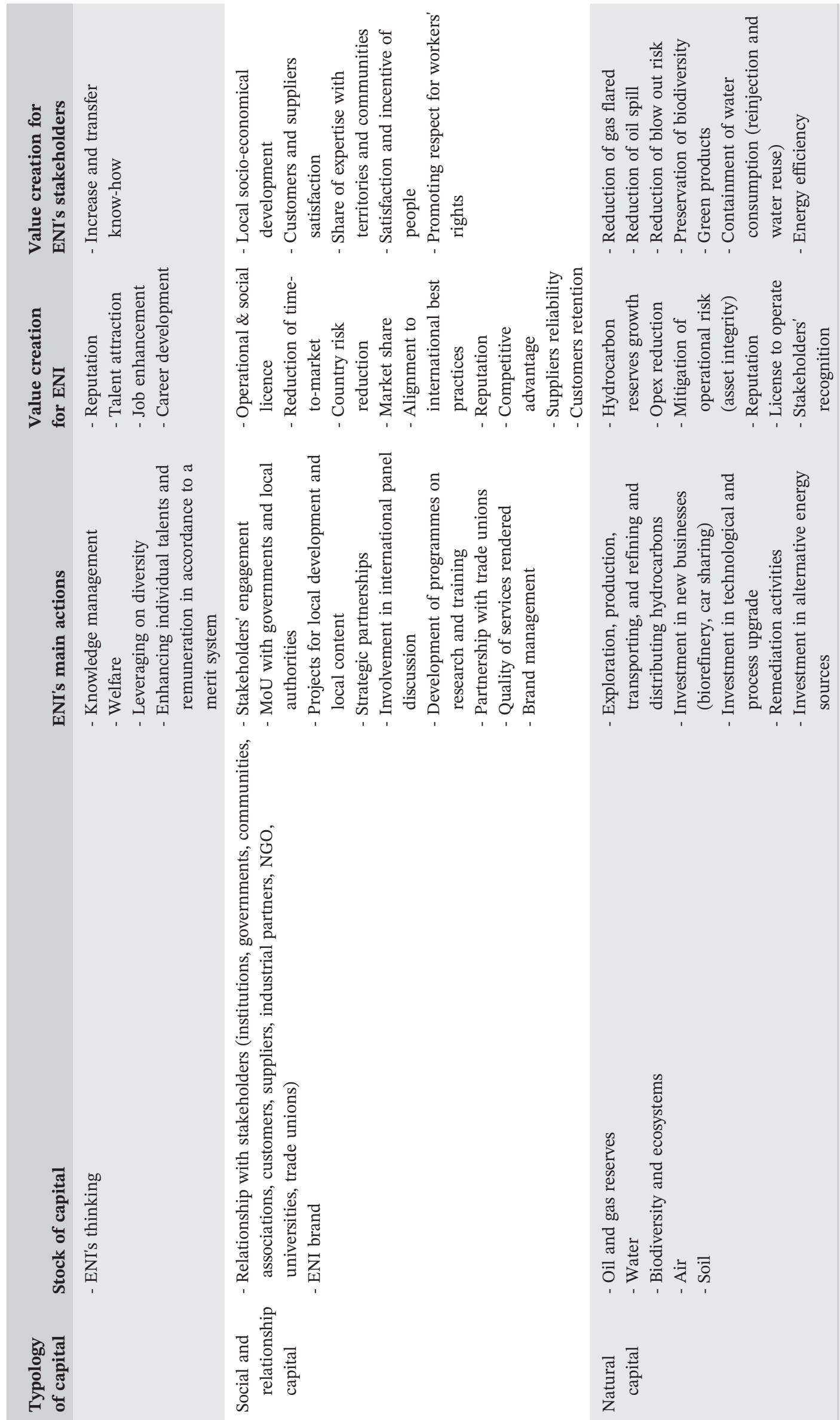
In more detail, to obtain the measures for dynamic complexity, it is useful to adopt the model assessment function related to variables types, feedback loops, polarities, and relationships existing in SDM-Doc (MartinezMoyano, 2012), which is a tool able to analytically investigate the structure of an SD model.

Table 1 shows the generic steps that can be followed to replicate the study with other corporate reports.

\section{4 | RESULTS}

This section presents the resource map and the analysis of the dynamic complexity existing in ENI's business according to its $<\mathrm{IR}>$. The starting point of our exploration is briefly represented in Table 2 that describes the ENI's business model as presented in its $2015<\mathrm{IR}>$.

For each typology of capital identified (Financial, Productive, Intellectual, Human, Social and Relationship, and Natural), Table 2 reports the list of stocks (or capitals/resources) and the actions carried out by ENI to manage them. Outputs and outcomes, measured in terms of value creation, are subsequently classified into two typologies: Value created for ENI and Value created for ENI's stakeholders.

Building on the information displayed in Table 2, the resource map was developed, representing the process of value creation developed by ENI (Figure 2).

Specifically, this first simple map allowed identifying the key stocks of capital (black items), ENI's main actions to drive the stocks of capital (flows, in blue colour), and
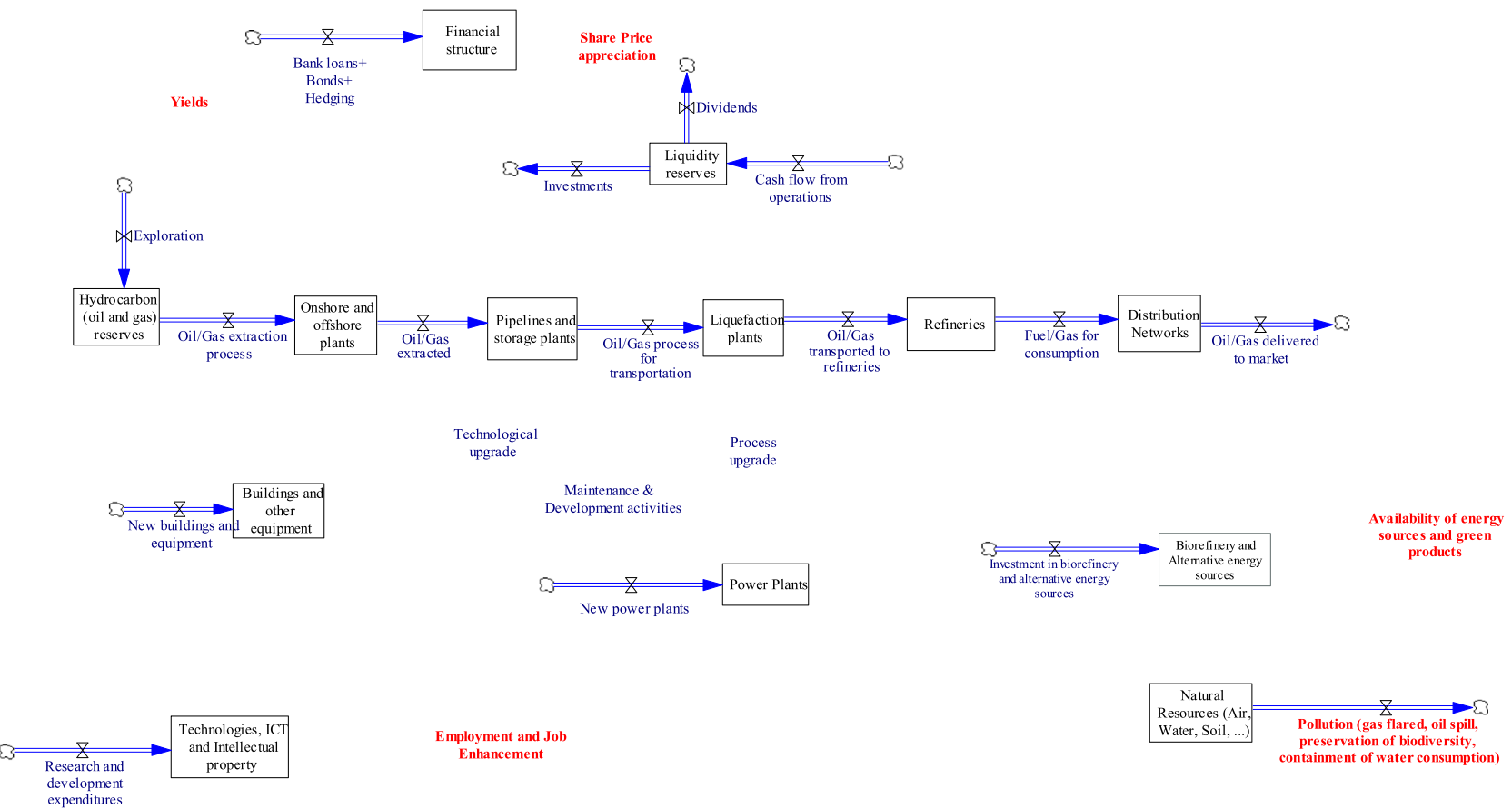
expenditure

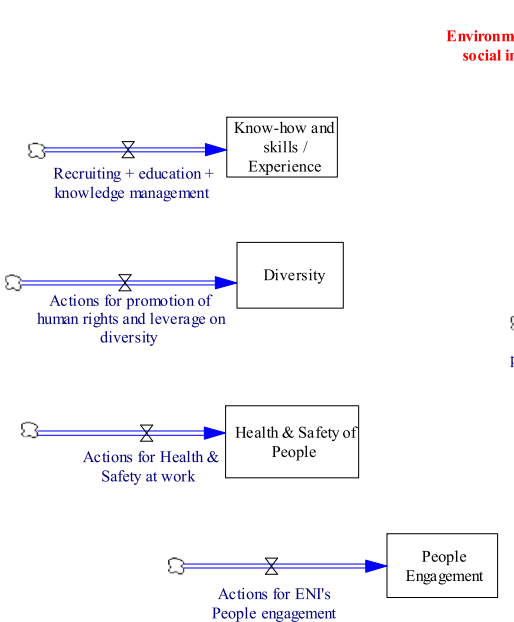

Environmental and social impacts

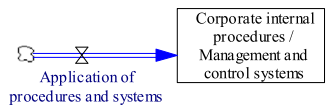

Transfer of best available hogies and know
host Countries

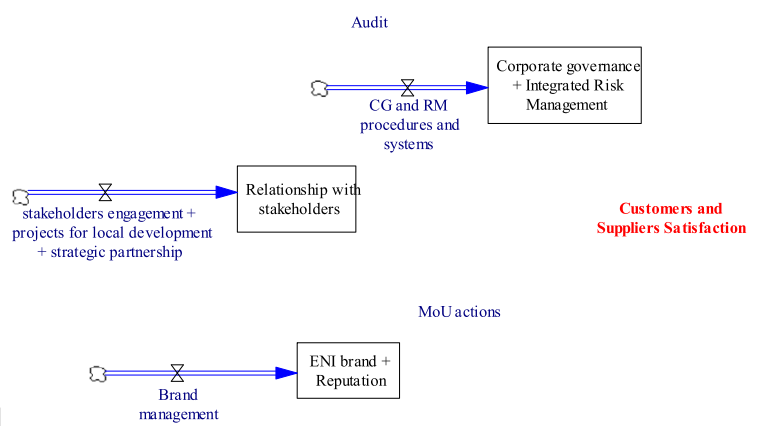

FIGURE 2 ENI's resource map based on the stocks of capital indicated in Table 2 [Colour figure can be viewed at wileyonlinelibrary.com] 
value creation outcomes for ENI's stakeholders (red items), together with processes and capabilities generated by the resources (additional blue items). The adoption of different colours is an artefact to make the resource map more intelligible and facilitate communication with nonexperts. The names of the resources (rectangles) are aligned to the stocks of capital displayed in Table 2, and the names of the flows (arrows with little valves) indicate the actions responsible for building the resources (ENI's main actions in Table 2). Some capitals shown in Table 2 were aggregated in our resource map, given their inherent similarity and common management (e.g., Air, Water, and Soil were merged into one single resourceNatural resources). This is a deliberate choice related to the level of detail adopted in illustrating the system of strategic resources comprising ENI and responsible for the process of value creation in the company.

Table 3 presents the 21 resources identified in the ENI's report.

Table 3 Typologies of integrated reporting capitals/ resources in the resource map

The successive step entailed the addition of causal relationships derived from the ENI's $<\mathrm{IR}>$. The source of the causal relationships was either a verbal description of the linkages between two concepts or the

TABLE 3 Typologies of integrated reporting capitals/resources in the resource map

\begin{tabular}{|c|c|}
\hline $\begin{array}{l}\text { Capitals in the } \\
\text { integrated report }\end{array}$ & $\begin{array}{l}\text { Resources in the } \\
\text { resource mapping }\end{array}$ \\
\hline Financial & $\begin{array}{l}\text { Financial structure } \\
\text { Liquidity reserves }\end{array}$ \\
\hline Productive & $\begin{array}{l}\text { Onshore and offshore plants } \\
\text { Pipelines and storage plants } \\
\text { Liquefaction plants } \\
\text { Refineries } \\
\text { Distribution networks } \\
\text { Power plants } \\
\text { Buildings and other equipment } \\
\text { Hydrocarbon (oil and gas) reserves }\end{array}$ \\
\hline Intellectual & $\begin{array}{l}\text { Technologies, ICT, and intellectual property } \\
\text { Corporate internal procedures/management } \\
\text { and control systems/ } \\
\text { Corporate governance + integrated risk } \\
\text { management }\end{array}$ \\
\hline Human & $\begin{array}{l}\text { Know-how and skills/experience } \\
\text { People engagement } \\
\text { Diversity } \\
\text { Health \& safety of people }\end{array}$ \\
\hline $\begin{array}{l}\text { Social and } \\
\text { relationship }\end{array}$ & $\begin{array}{l}\text { Relationship with stakeholders } \\
\text { ENI brand + reputation }\end{array}$ \\
\hline Natural & $\begin{array}{l}\text { Natural resources (air, water, soil, ...) } \\
\text { Biorefinery and alternative energy sources }\end{array}$ \\
\hline
\end{tabular}

graphical display of information such as in Table 2 . Each causal relationship is assigned a "polarity," either positive $(+)$ for an influence in the same sense of direction (e.g., positive slope) or negative (-) for an effect in the opposite directions (e.g., negative slope; Senge, 1990). The polarity was identified by observing the verbs employed describing the linkages of two variables or inferred from basic accounting principles (Tables A.1 and A.2 in the Appendix show all the positive and negative linkages identified). As an example, Figure 3 portrays the upper part of the resource map (shadow variables are in grey colour).

The analysis of the dynamic complexity represented in the resource map displays that ENI's value creation process is driven by mostly positive linkages between variables (96 linkages mostly concentrated in the productive and human capital areas) rather than by negative links (28 linkages mostly in the productive capital area). Business processes generate cash that is reinvested in the business growing the resources even more and leading to positive linkages and outcomes. Managerial actions drive tangible and intangible resources to generate value creation processes. Thus, value creation is a positive feedback process driven by managers to perpetuate the growth of a company over time and create value for a variety of internal and external stakeholders.

As shown in the complete resource map (Figure 4), negative linkages are usually cost-related to either financial or environmental impacts rather than negative effects from resources constraining the business. There is only one exception in the case of investments in technologies, which has a negative link as it reduces the negative impact of environmentally damaging activities. These results illustrate the basic principle in financial accounting that costs are negative for the business profitability so it is important to contain them. It is also noteworthy that no negative polarities involve variables from the human capital illustrating the basic principle of knowledge resources are scale-free resources. Scale-free resources are resources with the potential to be used in multiple applications without affecting their usability, for example, not curtailing the positive feedback loops in a business.

The adoption of the SDM-Doc software allows evaluating the dynamic complexity responsible for value creation. First, there are 61 concepts (21 resources and 40 capabilities and factors, with 24 investment and operational processes) connected through 124 causal links which generate 301 feedback loops. Additionally, the analysis reveals that ENI's strategy is heavily anchored in a large number of positive feedback loops: there are 254 positive (or reinforcing) and just 47 negative (or balancing) feedback loops. 


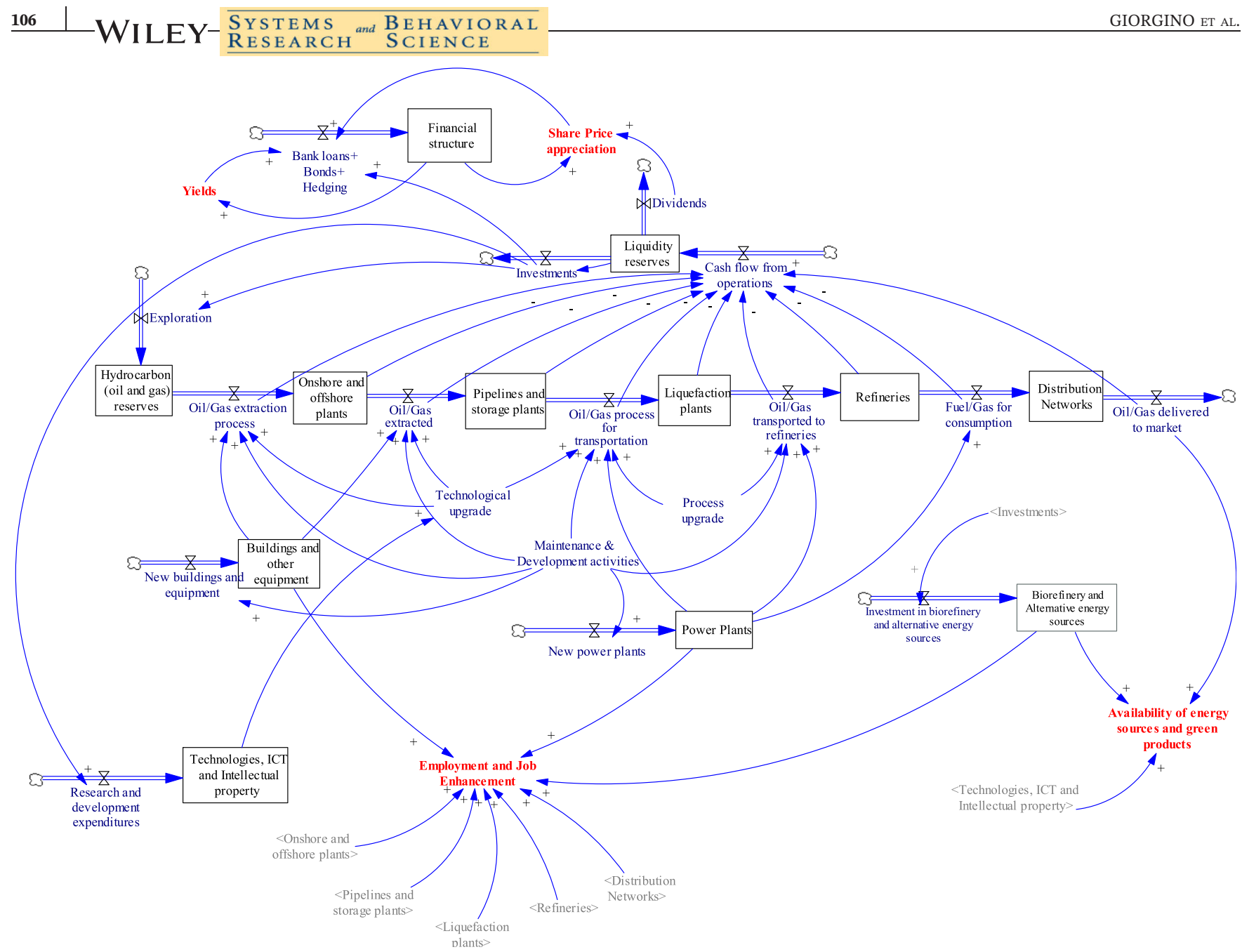

FIGURE 3 ENI's resource map (upper part) [Colour figure can be viewed at wileyonlinelibrary.com]

Table 4 shows the number (and relative percentage) of feedback loops affecting each of the capitals/resources and, subsequently, classified according to their typology (positive and negative). These data can identify resources that are most relevant to ENI's value creation. Additionally, Table 4 indicates further information useful to understand the resource relevance in terms of model structure, as discussed in the research methodology. With 21 resources, the system is a highorder system whose behaviour is difficult to predict due to extensive cause-effect chains and a high number of very long feedback loops. However, the business seems to be concentrated in key hotspots of activity given their high density of feedback loops. In our case study, as shown by Table 4, the critical resources are Liquidity reserves and Know-how, skills, and experience, which concentrate approximately $82 \%$ of the feedback loops, and are characterized by a fairly similar proportion of positive and negative feedback loops, with ratios between positive and negative loops of 6.03 and 5.68, respectively. Moreover, results highlight that the ENI's resources with the highest ratios belong to the productive capital, for example, hydrocarbon (oil and gas) reserves with a ratio of 12.33 . Among the other resources that can be considered as intangible, the highest numbers of feedback loops refer to technologies, ICT, and intellectual property (163) and corporate internal procedures/management and control systems (122). Notably, the two resources aforementioned also display quite similar ratios (respectively, 5.04 and 3.52). Interestingly, natural resources are not part of any feedback loop, and related activities, such as environmental and social impacts, are just in only one feedback loop.

Table 5 presents the same information organized in Table 4, however in reference to the other variables (or concepts) of the resource map. There are some concepts that stand out for the number of loops going through them: two related to the financial capital (investments and cash flow from operations) and two to the human capital (employment and job enhancement and recruiting + education + knowledge management) but there are quite dissimilar ratios.

Table 5 confirms that the minimum and the maximum number of variables per loop are respectively of 3-23 for 


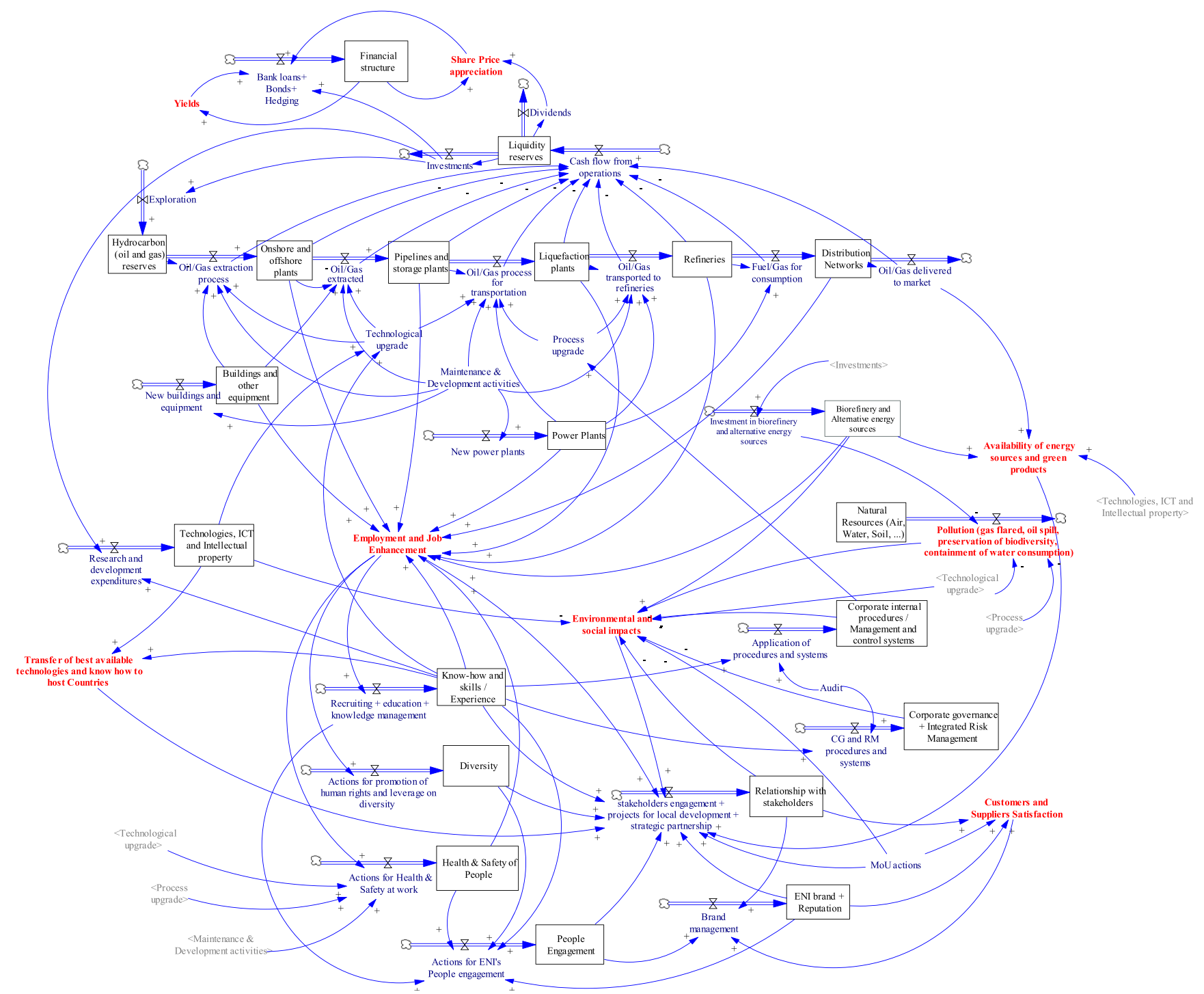

FIGURE 4 ENI's complete resource map [Colour figure can be viewed at wileyonlinelibrary.com]

positive loops and 2-21 for negative loops. As underlined, loop length not only can be employed to evaluate the structural complexity of a mental model corresponding to a specific dynamic system under analysis (see Schaffernicht \& Groesser, 2014), but it can also be considered as a proxy of how the effects of our actions (in this case, value creation stemming from the organization's policies) occur across the business domain under analysis (see Verburgh, 1994). In detail, longer loops are more likely (than shorter loops) to span across the whole business domain, involving various stakeholders, organizational layers, and geographical areas. Subsequently, they could play a relevant role in revealing hidden pathways for value creation, or paths of value creation, which will require a definite effort by the organization management to be properly exploited.

Interestingly, Table 5 also shows that there is an important number of concepts that do not have any feedback loop associated with them offering the impression of ad hoc activities.

\section{5 | DISCUSSION}

According to our research questions, this study primarily offers evidence on how adopting qualitative SD techniques to reframe the information are embedded in corporate reports and provide new knowledge in terms of corporate reporting. In this context, the combination of $<$ IR $>$ with qualitative SD (specifically with resource mapping) is suitable to support visualizing organizational capitals (or resources) and their interconnections to communicate the unique value-creation story of the organization in a comprehensive and transparent way (Barnabè, 2016). Specifically, the development of the $<\mathrm{IR}>$-based resource map requires the critical reinterpretation and 


\section{定}

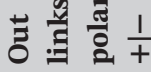
है

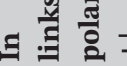

$\stackrel{\bar{z}}{\Xi}$

范

윽윽 큭킄ㅋㅋ킄ㅋ윽윽 윽 윽

鬲

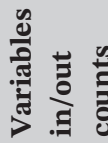

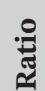

$\frac{1}{+}$

읏 읏 응 으⿱ 응응윽 윽욱 응 윽 읏

$\stackrel{\circ}{\circ} \frac{\circ}{\infty} \stackrel{\circ}{\circ} \frac{\circ}{N} \stackrel{\circ}{\frac{0}{m}} \frac{\circ}{m} \frac{\circ}{m}$

윽 윽윽윽윽 윽윽 윽

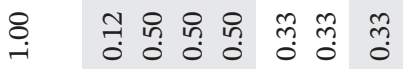

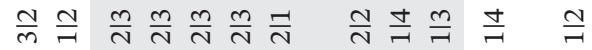

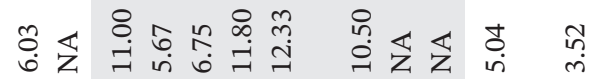

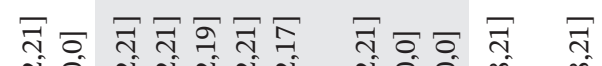

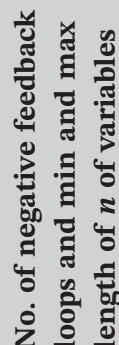

范

ङूँ

늃

党

क्षे

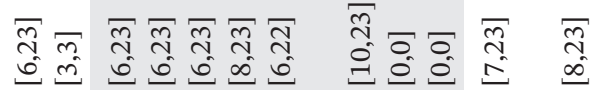

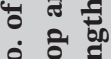

z :

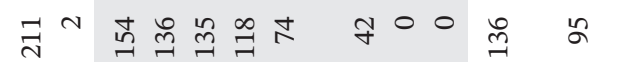

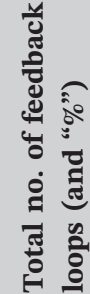

ส.

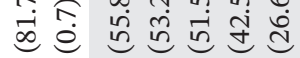

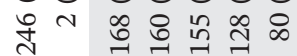

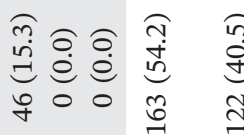

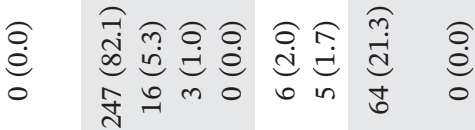

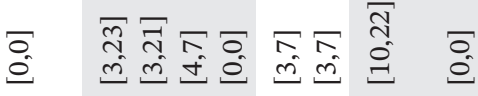

- 근 $\operatorname{ta} 0$ in in

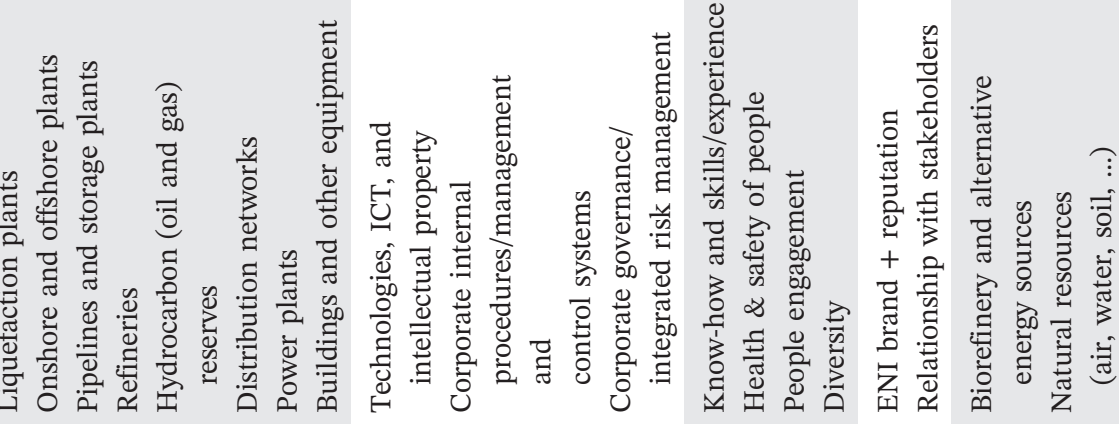

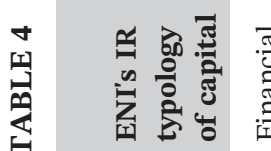

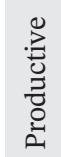

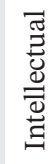
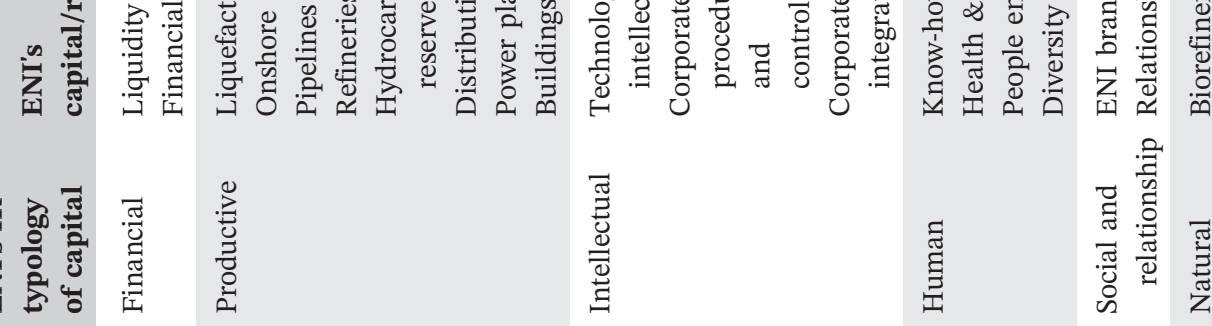


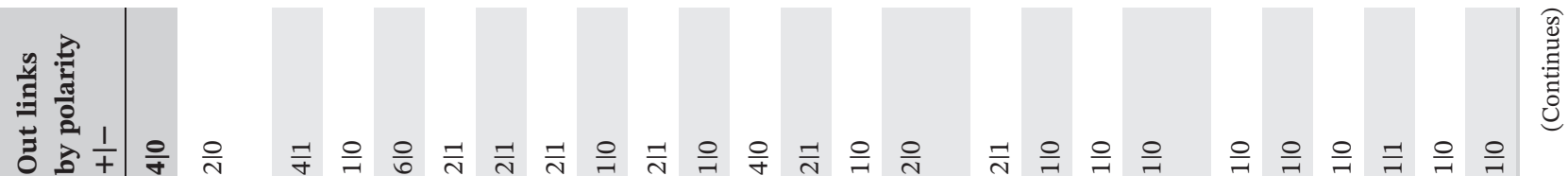

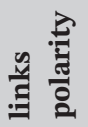

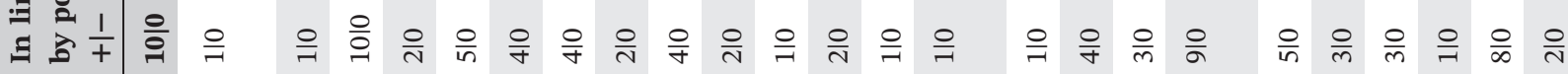
芩

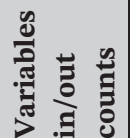

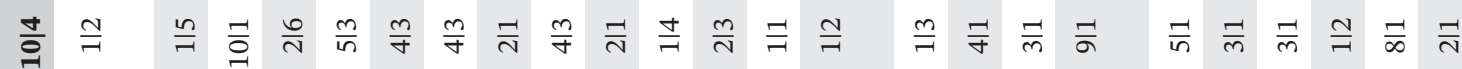

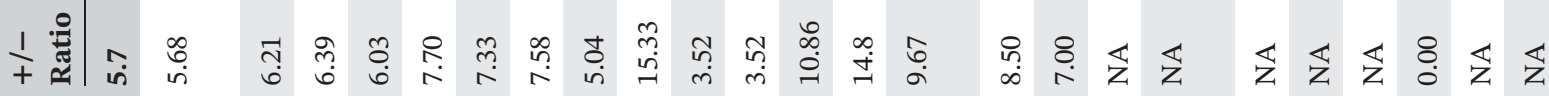

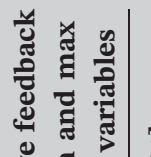

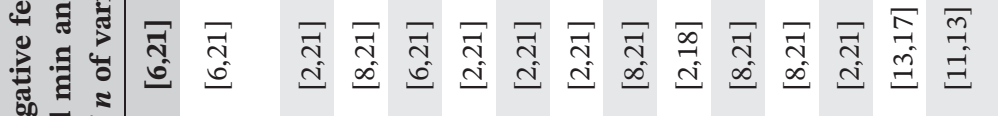

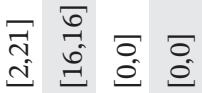

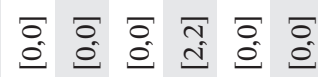

ż छ

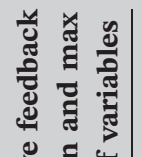

শె

๗ָत

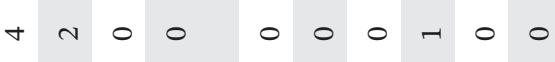

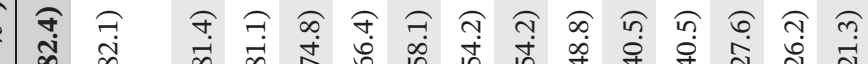

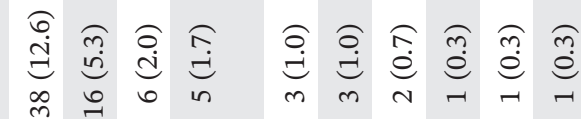

苟

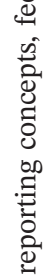

营

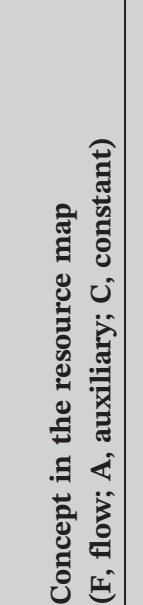



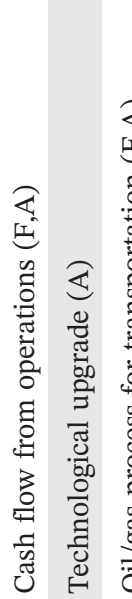

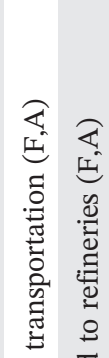

这这

$$
\text { (n) }
$$




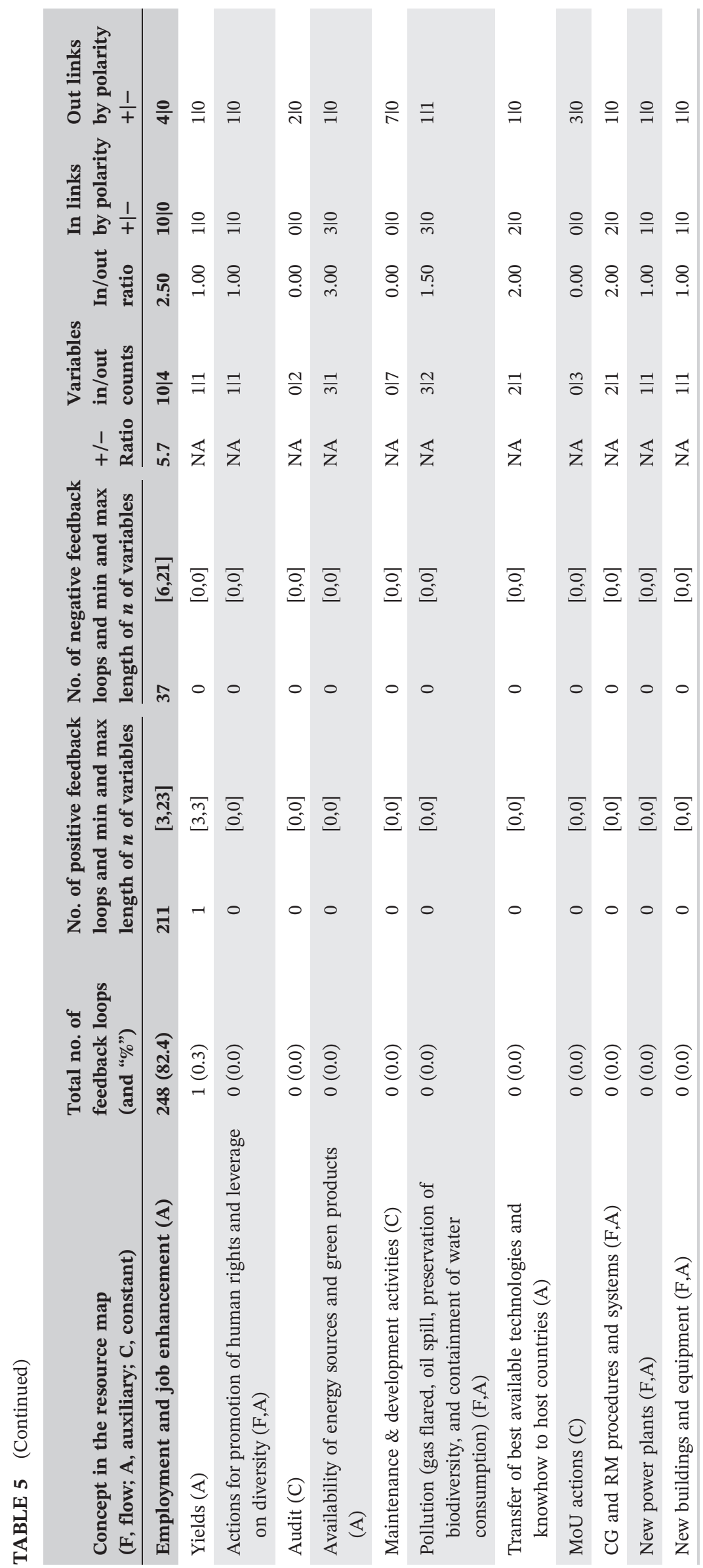


reframing of the report data according to the qualitative SD perspective to represent the business architecture in terms of capitals/resources supported by investment processes and interconnected through the use of positive and negative causal relationships to identify critical elements, hotspots, in the business.

This is coherent with the literature, emphasizing that the main goal of using qualitative SD is not to develop a fully working model able to reproduce the behaviour of a given system, rather support decision-makers, clients, and stakeholders, creating "a shared language for mutual understanding” (Vennix, 1996, p. 109), gain policy insights (Lane, 2012), foster consensus, "stimulate, feed, and structure the debate" (Pala et al., 2003, p. 706), and provide the conditions for "a useful exercise, [through which] a given problem is effectively «solved» in the sense that the insights from the diagram are so convincing that managers are prepared to act on them without a quantified analysis" (Coyle \& Alexander, 1997, p. 206).

The $<\mathrm{IR}>$-based resource map also provides an analytic explanation of the systemic structure of reference, therefore generating new knowledge suitable to:

- support decision-making with integrated thinking which is a key feature of $<\mathrm{IR}>$ (IIRC, 2013a) and a feedback process-oriented approach (Kazakov \& Kunc, 2016; Kunc \& Morecroft, 2007);

- identify trade-offs between capitals and explore how actions focused on one capital may affect other capitals (de Villiers et al., 2014);

- assist managers and decision-makers in figuring out the consequences of their actions and understand that short, medium, and long-term outcomes of decisions can vary, or even be counterintuitive (Forrester, 1971);

- explore how an organization may create value in a multi-stakeholder and holistic perspective, eventually facilitating stakeholders' participation in management decisions (e.g., Stave, 2002).

With respect to the second aim of this study, that is, verify the potentials of qualitative SD in inspecting the dynamic complexity expressed in a comprehensive corporate report, the analysis of the $<\mathrm{IR}>$-based resource map provides useful insights. In this regard, the $<\mathrm{IR}>$-based resource map represents the structure of feedback processes governing the business. This would eventually allow managers to move away from the more traditional view of business as systems governed by linear thinking and event-oriented representations, towards the consideration of their business as a complex domain, to be analysed in a feedback-oriented and multi-actor perspective. Adopting the qualitative SD approach to the business domain reaffirms the need to manage simultaneously multiple organizational resources to create value in a holistic perspective (Kunc \& Morecroft, 2010)

Additionally, our analysis and the use of the SD model documentation software allows analysing and investigating relevant features of an enriched resource map, that is, density, corresponding to the number of loops going through a resource. The resources that contain most of the feedback loops become critical, hotspot for value creation, for the organization because they are considered indispensable for most of the business processes. The information on the length of loops can be considered as a proxy of the distance existing within a given system between an action being carried out and the result that is the most distant from the origin. Indeed, as Senge (1990, p. 71) points out, "dynamic complexity is present when an action has one set of consequences locally and a very different set of consequences in another part of the system ... [or] when obvious interventions produce nonobvious consequences". In this perspective, the analysis of the length of feedback loops contributes to operationalize the structural representation of the mental model implicitly disclosed in an $<\mathrm{IR}>$ and increases the awareness about the consequence of a change throughout the dynamic system (Groesser \& Schaffernicht, 2012; Verburgh, 1994).

To summarize, density and length of loops are properties of the underlying managers' mental models, now revealed through the process of reframing allowed by the resource map.

In brief, an integrated report, enhanced with resource mapping, offers an explanation of how a specific business is structured and operated, making clear and visible the complex hierarchy of capitals/resources-and their causal connections - at the organization's disposal, acting as a tool to boost the organization's ability to generate value under dynamic complexity (Kunc \& Morecroft, 2010). Notably, our results also demonstrate how a combined use of the $<\mathrm{IR}>$ concepts and guidelines, together with a qualitative SD map (the resource map), may reduce the burden of data collection and modelling and improve the focus on the components of the business and the dynamic complexity generated by their interactions (Wolstenholme, 1999).

\section{6 | CONCLUSION}

Because Gary et al. (2008) presented a view of the contribution of SD to strategy, there have been important advances in this area. More recently, articles in the management literature have demonstrated an increasing acceptance of SD for research in the area of resource- 
based modelling and mental models (e.g., Gary \& Wood, 2011; Kunc \& Morecroft, 2010). However, there are fewer developments in the area of corporate reporting. This article contributes to expanding the previous literature on the application of qualitative SD in the field of management accounting, providing additional evidence on the procedure and potential use of integrating a qualitative perspective into the practices of corporate reporting. Specifically, the combination of $<\mathrm{IR}>$ and resource mapping, as an example of integrating qualitative SD into accounting, can provide important contributions to reframing corporate reporting information into new knowledge, hence, revealing the dynamic complexity embedded in business models and its impact on value creation (Kazakov \& Kunc, 2016). Therefore, this article may represent a first step in a new approach to complement traditional accounting reporting with selected information related to the dynamic complexity embedded in the business such as the ratio between positive and negative feedback loops and the density of feedback loops in critical components of the business.

This study has some limitations that provide the basis for future research. First, the study is only applied to one company and by one team of researchers. Future work can make comparative studies using more than one company (also belonging to different industries), and more than one team can work in parallel to cross-evaluate their resource maps. Second, the study analysed one report so there is not enough evidence to suggest that the dynamic complexity here represented reflects all of the deep interconnections among variables affecting the organization's value creation. Future work should compare multiple reports over time and generate a unique resource map reflecting the most common elements. Third, our study is based on the development of a qualitative resource map. Not all of the characters defining dynamic complexity can be fully represented and embedded into this representation (e.g., the presence and effect of time delays and nonlinearities, history dependency, and side-effects of policies).

\section{REFERENCES}

Adams, C. A. (2015). The international integrated reporting council: A call to action. Critical Perspectives on Accounting, 27(1), 23-28. https://doi.org/10.1016/j.cpa.2014.07.001

Akkermans, H. A., \& Van Oorschot, K. E. (2005). Relevance assumed: A case study of balanced scorecard development using system dynamics. Journal of the Operational Research Society, 56(8), 931-941. https://doi.org/10.1057/palgrave.jors.2601923

Barnabè, F. (2016). "Representing” value creation: A combined approach of system dynamics and integrated reporting for the airline sector. International Journal of Applied Systemic Studies, 6(3), 202-222. https://doi.org/10.1504/IJASS.2016.079085
Barnabè, F., \& Busco, C. (2012). The causal relationships between performance drivers and outcomes: Reinforcing balanced scorecards' implementation through system dynamics models. Journal of Accounting and Organizational Change, 8(4), 528-538. https://doi.org/10.1108/18325911211273518

Barney, J. B. (1986). Strategic factor markets: Expectations, luck and business strategy. Management Science, 32(10), 1231-1241. https://doi.org/10.1287/mnsc.32.10.1231

Capelo, C., \& Ferreira Dias, J. (2009). A system dynamics-based simulation experiment for testing mental model and performance effects of using the balanced scorecard. System Dynamics Review, 25(1), 1-34. https://doi.org/10.1002/sdr.413

Coyle, R. G., \& Alexander, M. D. W. (1997). Two approaches to qualitative modelling of a nation's drugs trade. System Dynamics Review, 13(3), 205-222. https://doi.org/10.1002/(SICI)10991727(199723)13:3<205::AID-SDR126>3.0.CO;2-P

Deegan, C., \& Blomquist, C. (2006). Stakeholder influence on corporate reporting: an exploration of the interaction between WWFAustralia and the Australian minerals industry. Accounting, Organizations and Society, 31(4-5), 343-372. https://doi.org/ 10.1016/j.aos.2005.04.001

Dierickx, I., \& Cool, K. (1989). Asset stock accumulation and sustainability of competitive advantage. Management Science, 35(12), 1504-1511. https://doi.org/10.1287/mnsc.35.12.1504

Doyle, J. K., Radzicki, M. J., \& Trees, W. S. (2008). Measuring change in mental models of complex dynamic systems. In $\mathrm{H}$. Qudrat-Ullah, M. J. Spector, \& P. Davidsen (Eds.), Complex decision making: Theory and practice (pp. 269-294). Berlin: SpringerVerlag.

Eberlein, R. L., \& Peterson, D. W. (1992). Understanding models with Vensim ${ }^{\mathrm{TM}}$. European Journal of Operational Research, 59(1), 216-219. https://doi.org/10.1016/0377-2217(92)90018-5

Eccles, R. G., \& Krzus, M. P. (2011). One Report. In Integrated Reporting for a Sustainable Strategy. New York: Wiley and Sons.

Eden, C. (1992). On the nature of cognitive maps. Journal of Management Studies, 29(3), 261-265. https://doi.org/10.1111/j.14676486.1992.tb00664.x

ENI. (2015). Integrated Annual Report 2015, Roma. Retrieved November 10, 2016, from https://www.eni.com/docs/en_IT/ enicom/company/integrated-annual-report-2015.pdf.

Ford, D., \& Sterman, J. D. (1998). Expert knowledge elicitation for improving mental and formal models. System Dynamics Review, 14(4), 309-340. https://doi.org/10.1002/(SICI)1099-1727(199824) 14:4<309::AID-SDR154>3.0.CO;2-5

Forrester, J. W. (1961). Industrial dynamics. Cambridge: The M.I.T. Press.

Forrester, J. W. (1968). Principle of systems. Cambridge: The M.I.T. Press.

Forrester, J. W. (1971). Counterintuitive behavior of social systems. Technology Review, 73(3), 52-68.

Forrester, J. W. (1980). Information sources for modeling the national economy. Journal of the American Statistical Association, 75(371), 555-566. https://doi.org/10.1080/01621459.1980. 10477508

Gary, M. S., Kunc, M., Morecroft, J. D. W., \& Rockart, S. F. (2008). System dynamics and strategy. System Dynamics Review, 24(4), 407-429. https://doi.org/10.1002/sdr.402 
Gary, M. S., \& Wood, R. E. (2011). Mental models, decision rules, and performance heterogeneity. Strategic Management Journal, 32(6), 569-594. https://doi.org/10.1002/smj.899

Giorgino, M. C., Supino, E., \& Barnabè, F. (2017). Corporate disclosure, materiality, and integrated report: An event study analysis. Sustainability, 9(12), 2182. https://doi.org/10.3390/su9122182

Gray, R., Kouhy, R., \& Lavers, S. (1995). Corporate social and environmental reporting: A review of the literature and a longitudinal study of UK disclosure. Accounting, Auditing \& Accountability Journal, 8(2), 47-77. https://doi.org/10.1108/ 09513579510146996

Groesser, S. N. (2013). Co-evolution of standards in innovation systems: The dynamics of voluntary and legal building codes. Berlin: Springer. https://doi.org/10.1007/978-3-7908-2858-0

Groesser, S. N., \& Schaffernicht, M. (2012). Mental models of dynamic systems: Taking stock and looking ahead. System Dynamics Review, 28(1), 46-68. https://doi.org/10.1002/sdr.476

Größler, A. (2004). A content and process view on bounded rationality in system dynamics. Systems Research and Behavioral Science, 21(4), 319-330. https://doi.org/10.1002/sres.646

Humphreys, K. A., Gary, M. S., \& Trotman, K. T. (2015). Dynamic decision making using the balanced scorecard framework. The Accounting Review, 91(5), 1441-1465.

International Integrated Reporting Council (IIRC). (2013a). The international <IR $>$ framework. Retrieved December 20, 2016, from http://www.theiirc.org/international-ir-framework/.

International Integrated Reporting Council (IIRC). (2013b). Capitals. Background paper for $\langle\mathrm{IR}>$. Retrieved December 20, 2016, from http://integratedreporting.org/wp-content/uploads/ 2013/03/IR-Background-Paper-Capitals.pdf.

Kaplan, R. S. (2012). The balanced scorecard: comments on balanced scorecard commentaries. Journal of Accounting and Organizational Change, 8(4), 539-545. https://doi.org/10.1108/ 18325911211273527

Kazakov, R., \& Kunc, M. (2016). Foreseeing the dynamics of strategy: An anticipatory systems perspective. Systemic Practice and Action Research, 29(1), 1-25.

Kim, D. H. (2001). Organizing for learning strategies for knowledge creation and enduring change. Waltham: Pegasus Communications.

Kim, H., \& Andersen, D. F. (2012). Building confidence in causal maps generated from purposive text data: Mapping transcripts of the federal reserve. System Dynamics Review, 28(4), 311-328. https://doi.org/10.1002/sdr.1480

Kopainsky, B., \& Luna-Reyes, L. F. (2008). Closing the loop: Promoting synergies with other theory building approaches to improve system dynamics practice. Systems Research and Behavioral Science, 25(4), 471-486. https://doi.org/10.1002/sres.913

Kunc, M. (2007). Portraying managerial dynamic capabilities: A case study in the fast-moving consumer goods industry. International Journal of Learning and Intellectual Capital, 4(1-2), 92-110. https://doi.org/10.1504/IJLIC.2007.013825

Kunc, M., \& Morecroft, J. D. W. (2007). System dynamics modelling for strategic development. In R. Dyson, \& F. O'Brien (Eds.), Supporting strategy: Frameworks, methods and models (pp. 157-190). Chichester: John Wiley.
Kunc, M., \& Morecroft, J. D. W. (2009). Resource-based strategies and problem structuring: Using resource maps to manage resource systems. Journal of the Operational Research Society, 60(2), 191-199. https://doi.org/10.1057/palgrave.jors.2602551

Kunc, M., \& Morecroft, J. D. W. (2010). Managerial decisionmaking and firm performance under a resource-based paradigm. Strategic Management Journal, 31(11), 1164-1182. https://doi.org/10.1002/smj.858

Kunc, M., \& O'Brien, F. A. (2017). Exploring the development of a methodology for scenario use: Combining scenario and resource mapping approaches. Technological Forecasting and Social Change, 124, 150-159. https://doi.org/10.1016/j.techfore.2017. 03.018

Lacagnina, V., \& Provenzano, D. (2009). In Á. Matias, P. Nijkamp, \& M. Sarmento (Eds.), An optimized system dynamics approach for a hotel chain management (pp. 35-49). HD: Physica-Verlag.

Lacagnina, V., \& Provenzano, D. (2011). Hotel chain performance: A gravity-DEA approach. In Á. Matias, P. Nijkamp, \& M. Sarmento (Eds.), Tourism economics: Impact analysis (pp. 171-181). HD: Physica-Verlag.

Lane, D. C. (2008). The emergence and use of diagramming in system dynamics: A critical account. Systems Research and Behavioral Science, 25(1), 3-23. https://doi.org/10.1002/sres.826

Lane, D. C. (2012). What is a "policy insight"? Systems Research and Behavioral Science, 29(6), 590-595. https://doi.org/10.1002/sres. 2148

Luna-Reyes, L. F., \& Andersen, D. L. (2003). Collecting and analyzing qualitative data for system dynamics: Methods and models. System Dynamics Review, 19(4), 271-296. https://doi.org/10. 1002/sdr.280

Martinez-Moyano, I. J. (2012). Documentation for model transparency. System Dynamics Review, 28(2), 199-208. https://doi.org/ 10.1002/sdr.1471

Miles, M. B., Huberman, A. M., \& Saldana, J. (2013). Qualitative data analysis. In $A$ methods sourcebook. London: Sage Publications.

Morecroft, J. D. W. (2007). Strategic modelling and business dynamics. Chichester: Wiley.

Pala, Ö., Vennix, J. A. M., \& Van Mullekom, T. (2003). Validity in SSM: neglected areas. Journal of the Operational Research Society, 54(7), 706-712. https://doi.org/10.1057/palgrave.jors. 2601577

Richardson, G. P., \& Pugh, A. (1981). Introduction to system dynamics modeling with dynamo. Waltham: Pegasus Communications.

Roca, L. C., \& Searcy, C. (2012). An analysis of indicators disclosed in corporate sustainability reports. Journal of Cleaner Production, 20(1), 103-118. https://doi.org/10.1016/j.jclepro. 2011.08.002

Ryan, B., Scapens, R. W., \& Theobald, M. (2002). Research method \& methodology in finance and accounting (2nd ed.). London: Thomson.

Schaffernicht, M. (2010). Causal loop diagrams between structure and behaviour: A critical analysis of the relationship between polarity, behaviour and events. Systems Research and Behavioral Science, 27(6), 653-666. https://doi.org/10.1002/sres.1018

Schaffernicht, M., \& Groesser, S. N. (2011). A comprehensive method for comparing mental models of dynamic systems. 
European Journal of Operational Research, 210(1), 57-67. https://doi.org/10.1016/j.ejor.2010.09.003

Schaffernicht, M., \& Groesser, S. N. (2014). The SEXTANT software: A tool for automating the comparative analysis of mental models of dynamic systems. European Journal of Operational Research, 238(2), 566-678. https://doi.org/10.1016/j.ejor.2014. 04.002

Senge, P. M. (1990). "The fifth discipline," the art and practice of the learning organization. NY: Doubleday-Currency.

Snabe, B., \& Größler, A. (2006). System dynamics modelling for strategy implementation-case study and issues. Systems Research and Behavioral Science, 23(4), 467-481. https://doi. org/10.1002/sres.773

Spector, J. M., Christensen, D. L., Sioutine, A. V., \& McCormack, D. (2001). Models and simulations for learning in complex domains: Using causal loop diagrams for assessment and evaluation. Computers in Human Behavior, 17(5), 517-545. https:// doi.org/10.1016/S0747-5632(01)00025-5

Stave, K. A. (2002). Using system dynamics to improve public participation in environmental decisions. System Dynamics Review, 18(2), 139-167. https://doi.org/10.1002/sdr.237

Sterman, J. D. (2000). Business dynamics. In System thinking and modeling for a complex world. Boston: McGraw-Hill.

Torres, J. P., Kunc, M., \& O'Brien, F. (2017). Supporting strategy using system dynamics. European Journal of Operational Research, 260(3), 1081-1094. https://doi.org/10.1016/j.ejor.2017. 01.018

Vennix, J. A. M. (1996). Group model building, facilitating team learning using system dynamics. Chichester: Wiley.
Verburgh, L. (1994). Participative policy modeling applied to the health care insurance industry. Netherlands: $\mathrm{PhD}$ thesis, University of Nijmegen.

de Villiers, C., Rinaldi, L., \& Unerman, J. (2014). Integrated Reporting: Insights, gaps and an agenda for future research. Accounting, Auditing \& Accountability Journal, 27(7), 1042-1067. https://doi.org/10.1108/AAAJ-06-2014-1736

Warren, K. (2008). Strategic management dynamics. Chichester: Wiley.

Wolstenholme, E. F. (1999). Qualitative vs quantitative modelling: The evolving balance. The Journal of Operational Research Society, 50(4), 422-428. https://doi.org/10.1057/palgrave.jors. 2600700

Wolstenholme, E. F., \& Coyle, R. G. (1983). The development of system dynamics as a methodology for system description and qualitative analysis. Journal of the Operational Research Society, 34(7), 569-581. https://doi.org/10.1057/jors.1983.137

Yin, R. K. (1994). Case study research: Design and methods (2nd ed.). Sage: Newbury Park, CA.

How to cite this article: Giorgino $\mathrm{MC}$, Barnabè $\mathrm{F}$, Kunc M. Integrating qualitative system dynamics with accounting practices: The case of integrated reporting and resource mapping. Syst Res Behav Sci. 2020;37:97-118. https://doi.org/10.1002/sres.2602

\section{APPENDIX A.}

TABLE A.1 Positive linkages in ENI's resource map

\section{Financial Capital}

Bank loans + bonds + hedging

Cash flow from operations

Dividends

Financial structure

Financial structure

Investments

Oil/gas delivered to market

Share Price appreciation

Yields

Productive Capital

Building and other equipment

Building and other equipment

Building and other equipment

Distribution networks
Financial structure

Liquidity reserves

Share price appreciation

Share price appreciation

Yields

Bank loans + bonds + hedging

Cash flow from operations

Bank loans + bonds + hedging

Bank loans + bonds + Hedging

Employment and job enhancement

Oil/gas extracted

Oil/gas extraction process

Employment and job enhancement
$+$

$+$

$+$

$+$

$+$

$+$

$+$

$+$

$+$

$+$

$+$

$+$

$+$ 
TABLE A.1 (Continued)

\section{Cause}

Exploration

Fuel/gas for consumption

Investments

Liquefaction plants

Maintenance \& development activities

Maintenance \& development activities

Maintenance \& development activities

Maintenance \& development activities

Maintenance \& development activities

Maintenance \& development activities

New buildings and equipment

New power plants

Oil/Gas extraction process

Oil/Gas extracted

Oil/Gas process for transportation

Oil/Gas transported to refineries

Onshore and offshore plants

Pipelines and storage plants

Power Plants

Power Plants

Power Plants

Power Plants

Process upgrade

Process upgrade

Refineries

Technological upgrade

Technological upgrade

Technological upgrade

Intellectual Capital

Application of procedures and systems

Audit

Audit

CG and RM procedures and systems

Corporate internal procedures/management and control systems

Investments

Research and development expenditures

Technologies, ICT and intellectual property

Technologies, ICT and intellectual property

Technologies, ICT and intellectual property
Effect

Polarity

Hydrocarbon (oil and gas) reserves

$+$

Distribution networks

Exploration

Employment and job enhancement

New buildings and equipment

New power plants

Oil/gas extracted

Oil/gas extraction process

Oil/gas process for transportation

Oil/gas transported to refineries

Buildings and other equipment

Power plants

Onshore and offshore plants

Pipelines and storage plants

Liquefaction plants

Refineries

Employment and job enhancement

Employment and job enhancement

Employment and job enhancement

Fuel/gas for consumption

Oil/gas process for transportation

Oil/gas transported to refineries

Oil/gas process for transportation

Oil/gas transported to refineries

Employment and job enhancement

Oil/gas extracted

Oil/gas extraction process

Oil/gas process for transportation

Corporate internal procedures/management + and control systems

Application of procedures and systems +

CG and RM procedures and systems

Corporate governance + integrated risk management +

Process upgrade

Research and development expenditures

Technologies, ICT, and intellectual property

Availability of energy sources and green products

Technological upgrade

Transfer of best available technologies and know how to + host countries
$+$

$+$

$+$

$+$

$+$

$+$

$+$ 
TABLE A.1 (Continued)

Cause

\section{Human Capital}

Actions for ENI's people engagement

Actions for health \& safety at work

Actions for promotion of human rights and leverage on diversity

Diversity

Employment and job enhancement

Employment and job enhancement

Employment and job enhancement

Health \& safety of people

Health \& safety of people

Maintenance \& development activities

Process upgrade

Recruiting + education + knowledge management

Recruiting + education + knowledge management

People engagement

People engagement

\section{Diversity}

Know-how and skills/experience

Know-how and skills/experience

Know-how and skills/experience

Know-how and skills/experience

Know-how and skills/experience

Know-how and skills/experience

Know-how and skills/experience

Know-how and skills/experience

Technological upgrade

Social and relationship capital

Availability of energy sources and green products

Brand management

Customers and suppliers satisfaction

Employment and job enhancement

ENI brand + Reputation

ENI brand + reputation

ENI brand + reputation
Effect

Polarity

People engagement

Health \& safety of people

Diversity

stakeholders engagement + projects for local development + strategic partnership

Actions for health \& safety at work

Actions for promotion of human rights and leverage on + diversity

Recruiting + education + knowledge management +

Actions for ENI's people engagement

Employment and job enhancement

Actions for health \& safety at work

Actions for health \& safety at work

Actions for ENI's people engagement

Know-how and skills/experience

Brand management

stakeholders engagement + projects for local development + strategic partnership

Actions for ENI's people engagement

Actions for ENI's people engagement

Application of procedures and systems

CG and RM procedures and systems

Employment and job enhancement

Research and development expenditures

stakeholders engagement + projects for local development + strategic partnership

Technological upgrade

Transfer of best available technologies and know how to + host countries

Actions for health \& safety at work

stakeholders engagement + projects for local development + strategic partnership

ENI brand + reputation

Brand management

stakeholders engagement + projects for local development + strategic partnership

Actions for ENI's people engagement +

Customers and suppliers satisfaction

stakeholders engagement + projects for local development + strategic partnership
$+$

$+$

$+$

$+$

$+$$$
+
$$$$
+
$$$$
+
$$$$
+
$$$$
+
$$$$
+
$$$$
+
$$$$
+
$$$$
+
$$$$
+
$$$$
+
$$$$
+
$$$$
+
$$$$
+
$$$$
+
$$$$
+
$$$$
+
$$$$
+
$$$$
+
$$$$
\text { . }
$$

$+$

$+$

$+$

$+$

$+$

$+$ 
TABLE A.1 (Continued)

\section{Cause}

Environmental and social impacts

MoU actions

MoU actions

Relationship with stakeholders

Relationship with stakeholders

Stakeholders engagement + projects for local development + strategic partnership

Transfer of best available technologies and know how to host countries

Natural capital

Biorefinery and alternative energy sources

Biorefinery and alternative energy sources

Investments

Investment in biorefinery and alternative energy sources

Oil/gas delivered to market

Pollution (gas flared, oil spill, preservation of biodiversity, and containment of water consumption)
Effect

Polarity

stakeholders engagement + projects for local

$+$ development + strategic partnership

Customers and suppliers satisfaction

$+$

stakeholders engagement + projects for local development + strategic partnership

Brand management

Customers and suppliers satisfaction

Relationship with stakeholders

stakeholders engagement + projects for local development + strategic partnership

Availability of energy sources and green products +

Employment and job enhancement

Investment in biorefinery and alternative energy sources + Biorefinery and alternative energy sources

Availability of energy sources and green products

Environmental and social impacts 
TABLE A.2 Negative linkages in ENI's resource map

Cause

Financial capital

Dividends

Fuel/gas for consumption

Investments

Oil/gas extracted

Oil/gas extraction process

Oil/gas process for transportation

Oil/gas transported to refineries

Productive capital

Fuel/gas for consumption

Liquefaction plants

Oil/gas delivered to market

Oil/gas extracted

Oil/gas extraction process

Oil/gas process for transportation

Oil/gas transported to refineries

Onshore and offshore plants

Pipelines and storage plants

Refineries

Intellectual capital

Corporate governance + integrated risk management

Corporate internal procedures/management and control systems

MoU actions

Technological upgrade

Technologies, ICT, and intellectual property

Human capital

No variables

Social and relationship capital

Relationship with stakeholders

Natural capital

Biorefinery and alternative energy sources

Investment in biorefinery and alternative energy sources

Pollution (gas flared, oil spill, preservation

of biodiversity, and containment of water consumption)

Process upgrade

Technological upgrade
Effect

Polarity

Liquidity reserves

Cash flow from operations

Liquidity reserves

Cash flow from operations

Cash flow from operations

Cash flow from operations

Cash flow from operations

Refineries

Cash flow from operations

Distribution Networks

Onshore and offshore plants

Hydrocarbon (oil and gas) reserves

Pipelines and storage plants

Liquefaction plants

Cash flow from operations

Cash flow from operations

Cash flow from operations

Environmental and social impacts

Environmental and social impacts

Environmental and social impacts

Environmental and social impacts

Environmental and social impacts

No variables

Environmental and social impacts

Environmental and social impacts

Pollution (gas flared, oil spill, preservation of biodiversity, and containment of water consumption)

Natural Resources (air, water, soil, ...)

Pollution (gas flared, oil spill, preservation of biodiversity, and containment of water consumption)

Pollution (gas flared, oil spill, preservation of biodiversity, and containment of water consumption) 